\title{
Fotografia w filmie "Powiększenie" Michelangelo Antonioniego
}

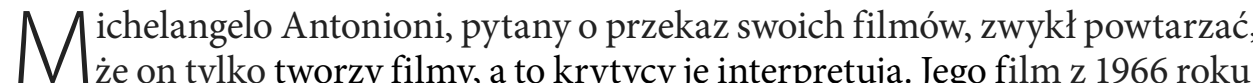
„Powiększenie” jest w istocie jednym z najbardziej znanych dzieł reżysera i do tej pory wzbudza interpretacyjne kontrowersje. Okazuje się bowiem, że oto obraz sprzed ponad pół wieku pozostaje nadal interesujący, mimo, że posługuje się prostą historią, mało wyraźnym bohaterem i nie wyjaśnioną intrygą. Właśnie te cechy stanowią o jego uniwersalności, a także estetycznej świeżości. Nie rażą w tym filmie ani dialogi, ani postacie, ani fabuła, ani przestrzeń, w której rozgrywa się akcja.

Dla autorki pracy najbardziej istotny w „Powiększeniu” jest autotematyzm. Film podejmuje problem samego medium, odnosząc się przede wszystkim do fotografii, ale również do malarstwa, czy pośrednio do literatury. Dziś, mimo ery przekazu cyfrowego, rozważania dotyczące natury analogowych zdjęć, nadal pozostają aktualne. Jednak refleksje Antonioniego są o wiele głębsze, a reżyser podejmuje próbę rozważenia problemu ludzkiej kondycji i bycia człowieka w świecie. Okazuje się bowiem, że ten mistrz włoskiego kina, zwany laickim moralistą, mimo dosyć ograniczonego dorobku, mimo, że bywały lata, kiedy jako twórca milczał, zostawił po sobie dzieła komentujące wciąż aktualne egzystencjalne dylematy. Od początku swojej kariery reżyser badał też możliwości samego medium filmowego. Jednak największe znaczenie dla rozwoju sztuki filmowej miało kwestionowanie konwencji filmowej i zasad dramaturgii. Nagle okazało się, że ani krwiste postacie, ani wartka akcja, czy jednoznaczne zakończenie nie konstytuują dzieła filmowego, że w filmie można posługiwać się ich zaprzeczeniem i dzięki temu powiedzieć o wiele więcej.

\footnotetext{
* Dr hab. Natasza ZióŁkowska-Kurczuk prof. Nazdw. - Zakład Dziennikarstwa UMCS; e-mail:natasza2663@poczta.onet.pl
} 
Filmy Antonioniego stają się zatem współczesnymi przypowieściami. Opowiadając z pozoru banalną historię, opisując codzienność bohatera, Antonioni porusza problemy ostateczne. Z pewnością zasługa tu mistrzów, z którymi współpracował na początku swej drogi twórczej. Współtworzył przecież scenariusze do filmów Roberta Rosselliniego, Giuseppe de Santisa i Federico Felliniego. Był asystentem francuskiego reżysera Marcela Carne przy głośnym filmie „Wieczorni goście”, a debiutował w 1943 roku dokumentem filmowym „Ludzie znad Padu”. Swój styl zaprezentował w filmie „Krzyk” z 1957 roku.

Dopiero jednak „Przygoda” zrealizowana w 1960 roku sprawiła, że Antonioni został szeroko zauważony. Filmu nie potrafiła zaakceptować publiczność i dała temu jednoznacznie negatywny wyraz podczas Festiwalu w Cannes, gdzie jednak obraz został nagrodzony przez jury i nominowany do Złotej Palmy. ${ }^{1}$ To jeden $\mathrm{z}$ tych przypadków, kiedy opinie widzów i krytyków poszły w diametralnie różnych kierunkach. Widzom trudno było zrozumieć fabułę. Oto główna bohaterka znika nagle podczas towarzyskiej wyprawy na wyspę i nie odnajduje się w finale filmu, co więcej, cała historia w ogóle nie zostaje wyjaśniona. Relacje różnych postaci tworzą niewyraźny, wieloznaczny obraz bohaterki i w sumie widz niczego konkretnego się o niej nie dowiaduje. Po raz pierwszy w swojej twórczości Antonioni stawia pytanie o granice ludzkiego poznania, a także o to na ile da się w ogóle poznać człowieka. Manifestuje w swoich późniejszych dziełach, że niezmiennym elementem świata jest moralność, dla której największe zagrożenie stanowi uczuciowa ułomność, brak związków międzyludzkich i samotność. Podejmuje też temat wyobcowania w tłumie, rozpaczy istnienia w świecie bez miłości i bez Boga. Nie tłumaczy, rzeczywistości, ale ją pokazuje. Jego kamera śledzi i rejestruje fragmenty świata i ludzkich losów. Reżyser pozbawia ją funkcji narratora, którego w jego filmach trudno jednoznacznie określić. Być może jest nim sam Antonioni. Widz, podobnie, jak bohater, nie zna całej filmowej rzeczywistości, a sposób prowadzenia narracji pozostawia go $\mathrm{z}$ tajemnicą. Dzieło staje się zatem metaforą ludzkiej egzystencji, składając się z przypadkowych zdarzeń i trywialnych gestów. Filmy Antonioniego kwestionują przyczynowo-skutkową dramaturgię zdarzeń i odwołując się do nowej dramaturgii, jak również do francuskiej antypowieści, tworzą swego rodzaju otwartą formę. Podobne problemy pojawiają się w filmie „Powiększenie”. Tu jednak reżyser poszerza swoje refleksje o autotematyzm, zastanawiając się nad naturą samego przekazu: filmu i fotografii, czy malarstwa.

W „Powiększeniu” pozornie dominuje fabularna intryga kryminalna. Antonioni iluzorycznie podejmuje próbę nakreślenia story i budowania narracji. Film opowiada o zbrodni, o której nie wiadomo, czy się naprawdę wydarzyła, czy jest

${ }^{1}$ Por. Książek-Konicka H., Michelangelo Antonioni, Wydawnictwa Artystyczne i Filmowe, Warszawa 1970. 
tylko złudzeniem, czy też swoistą grą, którą ktoś prowadzi z głównym bohaterem - fotografem Thomasem, a także $z$ widzem. Porusza się on w sztucznym, fałszywym świecie reklamy i mody, który jawi się jako kultura kliszy, gdzie wszystko wydaje się być fikcją i grą. Bohater to cyniczny i zarozumiały młody człowiek, dla którego aparat fotograficzny z jednej strony jest narzędziem poznania, a $z$ drugiej kreacji świata. Nawet, kiedy realizuje fotoreportaż w noclegowni dla bezdomnych mężczyzn posługuje się fikcją, przebierając się za jednego z nich. Realizuje te zdjęcia na czarno-białej kliszy, chcąc nadać im większej autentyczności. Kolor uczyniłby je zbyt banalnymi i niebezpiecznie zbliżył do wykreowanego świata mody i reklamy (co ciekawe współcześnie fotografowie mody również stosują tę formułę, łamiąc w ten sposób z kolei konwencję zdjęć modowych). Próbę tę podejmuje jednak głównie z powodów czysto estetycznych. $\mathrm{W}$ przygotowywanym właśnie autorskim albumie fotograficznym czarno-białe zdjęcia bezdomnych, robotników, a także zdegradowane społecznie postacie z zapuszczonych dzielnic Londynu, chce zestawić $\mathrm{z}$ ujęciami parku pozostającego w bezruchu. W rozmowie ze znajomym, Ronem, mówi o tych obrazach, a zarazem o swoim stosunku do pracy. Cytat podaję za ścieżką dźwiękową z filmu, ponieważ różni się on nieco od dialogu zapisanego w scenariuszu:

„THOMAS: (...) Bardzo spokojne, wręcz nieruchome. Reszta jest brutalna, więc to dobry finał.

RON: Będzie bardziej prawdziwie.

THOMAS: Wyjeżdżam z Londynu.

RON: Dlaczego?

THOMAS: Już mnie nie kręci. (...) Mam dość tych cholernych dziwek. Chciałbym mieć kupę forsy. Wtedy byłbym wolny.

RON: Wolny jak? Jak on?"2

Kamera pokazuje teraz zdjęcie pijanego biedaka, co ciekawe w jego roli występuje Julio Cortázar, autor opowiadania „Babie lato”, które stanowiło dla Antonioniego inspirację do napisania scenariusza filmu „Powiększenie”. W tym również przejawia się autotematyzm i to nie tylko dlatego, że znany argentyński pisarz mieszkający w Paryżu pojawia się w charakterze aktora, ale przede wszystkim dlatego, że jego opowiadanie traktuje o fotografii, a sam Cortázar również się nią parał. To rodzaj swoistej intertekstualnej gry, którą prowadzi Antonioni.

Świat wykreowany przez Thomasa, głównego bohatera „Powiększenia”, podczas realizacji sesji zdjęć mody, staje się plastikowym, tandetnym falsyfikatem, a fotografowi chodzi o to, żeby modelki przypominały manekiny. To zatarcie

${ }^{2}$ M. Antonioni, Powiększenie, film, prod. Carlo Ponti, dystr. MGM, 1966., gohttps://www.cda. $\mathrm{pl} /$ video/196190ec [dostęp: 18.05.2017]. 
granicy między kobietą-modelką, a kukłą widać również w ujęciach, gdzie bohater przygląda się wystawie ekskluzywnego butiku z modą kobiecą. W trakcie sesji zdjęciowej posługuje się taflami pleksiglasu, zafałszowuje przestrzeń, stosując odbicia. Dominuje w tych sztucznie wykreowanych fotografiach estetyka kiczu. Stanowić to może odniesienie do relacji bohatera $\mathrm{z}$ innymi ludźmi, w których nie ma nic prawdziwego, a zachowania erotyczne stają się jedynym instrumentem fizycznego zbliżenia. Pozbawione zostały one jednak zupełnie emocjonalnego zaangażowania. Dla Thomasa wykonywanie zdjęć i oglądanie pozujących modelek, to zmysłowy, niemal seksualny akt. Antonioni podkreśla to w filmie co najmniej dwa razy. Erotyczną grą jest scena z udziałem Veruschki, która $\mathrm{w}$ filmie gra samą siebie, czyli pierwszą niemiecką top modelkę. Jak słusznie zauważył Glenn O’Brien, to „czysty umysłowy seks”3 w najbardziej zmysłowej scenie sesji zdjęciowej w historii kina. Obraz filmowy montowany jest za pomocą stopklatki, tak, jakby na ułamek sekundy stawał się klatką w aparacie Thomasa. W akcie pozowania bohaterowie niemal się nie dotykają, ale fotograf mówi:

„THOMAS: Pokaż mi to. Pokaż wszystko"4

Następnie siada na Veruschce i lekko całuje ją w szyję, a kiedy udaje mu się uzyskać odpowiednią pozę, krzyczy:

„THOMAS: Teraz! Tak! Tak! Tak!"5

W końcu pada usatysfakcjonowany i zmęczony na kanapę, a modelka nadal wije się na podłodze nadmiernie rozbudzona erotycznie. Warto zwrócić uwagę na strój Veruschki, która jest ubrana, i rozebrana zarazem. Suknia i zakrywa, i odkrywa jej ciało, nie ukazując jednocześnie najważniejszych atrybutów kobiecości. Niedopowiedzenie działa tu o wiele silnej. Antonioni dał tutaj pokaz swoich umiejętności budowania napięcia dramaturgicznego, środka, którego świadomie w swoich filmach unika.

Być może ta scena miała być jednym z sygnałów wskazujących na oziębłość seksualną i emocjonalną bohatera. Podobnie jest w innych sekwencjach filmu. Kiedy Jane (Vanessa Redgrave) próbuje seksem niejako odkupić krępujące ją zdjęcia zrobione przez Thomasa w parku, Antonioni nagle wprowadza zakłócenie akcji w postaci posłańca, który właśnie dostarcza śmigło zakupione wcześniej przez bohatera $\mathrm{w}$ sklepie $\mathrm{z}$ antykami. Co ciekawe przy zakupie podkreślał on, że musi mieć je natychmiast, jakby od posiadania tego przedmiotu zależało jego

\footnotetext{
${ }^{3}$ https://i-d.vice.com/pl/article/powikszenie-jest-wci-najwikszym-filmem-modowym [18.05.2016].

${ }^{4}$ M. Antonioni, Powiększenie, op.cit.

${ }^{5}$ Ibidem.
} 
życie. Podobnie jest w scenie koncertu zespołu Yardbirds - brytyjskiej wschodzącej gwiazdy rocka. Publiczność podczas koncertu stoi nieruchomo, jakby pogrążona $w$ narkotycznym transie. Thomas leniwie błądzi w tym ludzkim labiryncie, po swoistym panopticum, by za chwilę, kiedy muzyk rozbije na scenie gitarę, rzucić się w wir walki o złamany gryf, który następnie z satysfakcją porzuci na ulicy. Thomas pożąda zatem bezużytecznych i okaleczonych przedmiotów. Ich posiadanie daje mu chwilową przyjemność. Można powiedzieć, że stanowią one surogaty rzeczywistości, pasji, surogaty marzeń, surogaty emocji. Bohater niezdolny do prawdziwych przeżyć poprzestaje na krótkotrwałym, prowizorycznym zadowoleniu, czy też, można powiedzieć, satysfakcji w sensie niemal erotycznym. Być może zarówno gryf gitary, jak i śmigło to swoiste fetysze. Przy czym należy stwierdzić za wieloma badaczami, m.in. za Ronaldem Barthesem, że fotografia jest bardziej fetyszystyczna niż kino, ponieważ w większym stopniu posługuje się fragmentem. Fetysz zyskuje przecież moc magiczną. ${ }^{6}$

$\mathrm{Na}$ impotencję bohatera wskazuje również scena $\mathrm{z}$ dwoma młodziutkimi modelkami - 20-letnią Jane Birkin (szatynka) i 21-letnią Gillian Hills (blondynka), które seksualną zabawę toczą pośród papierowego, fioletowego tła fotograficznego. Bardziej przypominają one rozebrane zapaśniczki niż dziewczyny, które próbują rozpocząć karierę modelek. Jak słusznie zauważa Paulina Wojtasik w tekście „Psychologia «Powiększenia»", że w filmie widać patriarchalny punkt widzenia: "To Thomas jest panem i władcą, to on mając aparat rządzi wszystkim, zwłaszcza kobietami. Pomimo tego boi się ich, o czym świadczyć może jego wymyślona żona i dzieci. (...) Bohater nie musi zdobywać kobiet, by czuć się w pełni zaspokojony. Zastępstwo znajduje nie tylko w fotografiach, ale także przeróżnych przedmiotach."” Autorka artykułu odwołuje się też do opinii Laury Mulvey, angielskiej reżyserki i producentki, a także profesora filmu i medioznawstawa w Birkbeck College w Londynie, że „Kobieta zatem jako ikona, pokazywana po to, aby podziwiali ją i cieszyli się nią mężczyźni, aktywni władcy spojrzenia, zawsze niesie za sobą groźbę, że wywoła strach, jaki pierwotnie oznaczała."8 Wydaje się, że ten pogląd jest tutaj wysoce uprawomocniony, na co wskazuje epatowanie seksem i eksponowanie cielesności kobiet, które stają się w rękach Thomasa przedmiotami. Można tu mówić o voyeuryzmie (rozumianym jako podglądactwo), czy o skoptofilii (rozumianej jako oglądactwo), gdzie przyjemność, również w znaczeniu seksualnym, czerpie się z patrzenia na innych. Fotografowanie, jak już wspomniano wcześniej, staje się dla bohatera czynnością seksualną.

\footnotetext{
${ }^{6}$ R. Barthes, Światło obrazu. Uwagi o fotografii, Warszawa, Wydawnictwo Alethia, 1996.

7 P. Wojtasik, Psychologia „Powiększenia”, http://www.racjonalista.pl/kk.php/s,4363 [dostęp 25.05.2017].

${ }^{8}$ L. Mulvey., Przyjemność wzrokowa a kino narracyjne, [w:] A. Helman, Panorama współczesnej myśli filmowej, Kraków 1992, Universitas, s. 102.
} 
Świat w filmie Antonioniego zapośredniczony zostaje przez medium. Thomas nie rozstaje się z aparatem i najczęściej przez obiektyw doświadcza świata, który tak naprawdę ogląda dopiero w ciemni na kliszy, albo na papierowym powiększeniu. Doświadcza świata poprzez obraz zapisany światłem. Na ile jest to obraz świata realnego, pozostaje w filmie tajemnicą.

Autorka pracy chciałaby jeszcze zwrócić uwagę na jedną, bardzo istotną kwestię, chociaż nie odnosi się ona może bezpośrednio do treści filmu, ale wkracza już w życie jednej z jego bohaterek - Veruschki. Otóż w przypadku jej życiorysu fotografia staje się narzędziem, które użyte zostało do transgresji, do przekroczenia norm społecznych i kształtowania poczucia tożsamości. Vera (Veruschka) Gottliebe Anna Gräfin von Lehndorff urodziła się tuż przed wybuchem II wojny światowej w starej rodzinie arystokratycznej pochodzącej z Prus Wschodnich. Siedzibą rodu był pałac w Sztynorcie. Jej ojciec, hrabia Heinrich Graf von Lehndorff-Steinort, był zaangażowany w nieudany zamach na Hitlera w 1944 roku w Wilczym Szańcu i został stracony w berlińskim więzieniu Plötzensee. Matka trafiła do obozu pracy, a Vera wraz z trzema siostrami do prowadzonego przez SS domu dziecka. Jeszcze przez wiele lat po wojnie prześladowała ją etykietka „córki mordercy”. W latach 60. Vera von Lehndorff dzięki wzrostowi $(1,83 \mathrm{~m})$ zaczęła robić karierę fotomodelki pod pseudonimem Veruschka. Jej styl wyprzedzał trendy lat 60. Była dzika i egzotyczna (taka, jaką pokazał ją Antonioni). Świat mody okrzyknął ją twarzą lat 60 . Na okładce Vouge’a znalazła się 11 razy. Była natchnieniem Richarda Avedona - jednego $\mathrm{z}$ najwspanialszych fotografów XX wieku, który nazwał ją najpiękniejszą kobietą na świecie. Zatem urodziła się jako hrabianka, potem została napiętnowana jako "córka mordercy", następnie uznana za mało atrakcyjną, by stać się ikoną mody i stylu. Właśnie dzięki fotografii Vera von Lehndorff mogła odrodzić się jako Veruschka i podbić świat, który odebrał jej tożsamość. Po latach jednak zdała sobie sprawę, że stała się przedmiotem i została wchłonięta przez komercyjny świat mody. Obecnie nadal jej twórczość odnosi się do własnego wizerunku, ponieważ Vera von Lehndorff jest jedną z pierwszych współczesnych artystek body paintingu. Wspólnie $\mathrm{z}$ fotografem, Holgerem Trülzschem, łączą fotografię z malarstwem, tworząc zdjęcia-kamuflaże, na których jej ciało pomalowane farbą stapia się z tłem budzącym u widzów uczucie dyskomfortu (np. złomowisko, zrujnowany budynek, zwał kamieni). Te dzieła stanowią też komentarz nie tylko do sytuacji kobiet-modelek, ale również wobec problemu niewidoczności kobiet w przestrzeni publicznej. ${ }^{9}$ Prace Very von Lehndorff stawiają również pytania, czy fotografia poszerza czy zawęża obraz świata. Co ciekawe, nad tym samym zastanawiał się przecież Antonioni.

9 Dziewiela E., Veruschka: życie w powiększeniu, http://www.harpersbazaar.pl/moda/1176/ veruschka-zycie-w-powiekszeniu [dostęp 25.05.2017.]. 
Film „Powiększenie”, jak każde dzieło związane z fotografią, czyli sztuką posługującą się reprodukowaną rzeczywistością, podejmuje problem śmierci. Już sam wątek kryminalny stanowiący zwornik akcji dotyczy morderstwa. Być może w ten sposób Antonioni chce przekazać myśl, że fotografia jest „zamrażaniem”, uśmiercaniem chwil. Można tę ideę powiązać z koncepcją mumifikacji rzeczywistości, która pojawiła się w rozważaniach Andre Bazina w tekście "Ontologia obrazu fotograficznego"10. Francuski teoretyk kina podkreśla, że ciągły strach przed rozkładem fizycznego ciała, przed unicestwieniem materii, popycha człowieka do ciągłego pozostawiania śladu swojego istnienia, a fotografia posiada zdolność przeniesienia w czasie jakiegoś fragmentu rzeczywistości, a jeśli chodzi o fotografię analogową - widma światła. Jak słusznie zauważył Zbigniew Tomaszczuk w swojej publikacji „Fotografia rzeczywistości - rzeczywistość fotograficzna”: „Pojęcie «balsamowania czasu» wprowadził Andre Bazin, wg którego fotografia nie tworzy rzeczywistości artystycznej jak sztuka, lecz balsamuje czas, ratując go przed samozniszczeniem. U podstaw refleksji Andre Bazina stała koncepcja, iż istotą popularności fotografii jest tęsknota człowieka za nieśmiertelnością w sferze symbolicznej. (...) Ciągłe poszukiwanie przez człowieka sposobów przedłużenia życia poprzez pozostawianie swojej obecności w postaci śladu, odcisku czy wizerunku plastycznego jest wg Bazina wynikiem „«kompleksu mumii», czyli kompleksu podobieństwa i potrzeba „«achowania» siebie dla potomności. (...) Istotą fotografii staje się potwierdzenie faktu «to było», a zatem w fotografiach chodzi o czas, a nie o formę, ponieważ najważniejszą kwestią jest, że stanowią one dla nas klisze pamięci." ${ }^{11}$ Nieco bardziej pesymistyczną wizję można znaleźć w rozważaniach Susan Sontag, kiedy pisze ona w słynnym eseju „O fotografii”: „Robiąc zdjęcie stykamy się ze śmiertelnością, kruchością, przemijalnością innej osoby lub rzeczy. Właśnie dlatego, że wybieramy jakąś chwilę, wykrawamy ją i zamrażamy, wszystkie zdjęcia stanowią świadectwo nieubłagalnego przemijania." 12

Film Antonioniego z perspektywy ponad półwiecza stanowić może niejako próbę zapisu świata, owego swingującego Londynu lat 60 . XX wieku, stolicy młodzieżowej mody, miejsca kulturowego wrzenia. Reżyser świadomie przenosi tu akcję z Paryża, gdzie dzieje się historia opisana przez Cortázara w opowiadaniu „Babie lato”, które stanowiło inspirację dla powstania scenariusza. Umieszcza w filmie czołowe postaci brytyjskiego pop-artu lat 60., tj. Peggy Moffit, Jane Birkin, Verushkę von Lehndorff, czy zespół Yardbirds. W filmie można zobaczyć

10 A. Bazin, Ontologia obrazu fotograficznego, za: http://residence.republika.pl/bazin,andrE9, ontologia, obrazu,fotograficznego.shtml [18.05.2017].

11 Z. Tomaszczuk, Fotografia rzeczywistości - rzeczywistość fotograficzna, [w:] PRACE NAUKOWE Akademii im. Jana Długosza w Częstochowie, Seria: „Edukacja Plastyczna” 2011, z. VI za: http:// dlibra.bg.ajd.czest.pl:8080/Content/1516/Plastyka_6-25.pdf [dostęp (18.05.2017].

12 S. Sontag, O fotografii, Kraków 2009, s. 23. 
ulice Soho czy Carnaby-Street, po których chodzą ludzie różnych narodowości, a także jeden $\mathrm{z}$ najmodniejszych klubów muzycznych, dom wiktoriański, w którym odbywa się przyjęcie, czy wreszcie urządzone w lofcie w wyludnionej robotniczej dzielnicy nowoczesne studio fotograficzne młodego popularnego fotografa. Co ciekawe, postać Thomasa była wzorowana na Davidzie Bailey’u, naczelnym fotografie Londynu lat 60 . Antonioni zaproponował mu nawet rolę samego siebie w „Powiększeniu”, ale ten odmówił. „Urodzony w londyńskiej robotniczej rodzinie, Bailey zasłynął jako najważniejszy dokumentalista gorączki swingującego Londynu lat 60. Jego fotograficzne portrety The Beatles i The Rolling Stones znał cały świat. Przyjaźnił się z Mickiem Jaggerem, Andym Warholem i Romanem Polańskim, a jego muzami i partnerkami w życiu prywatnym były najpiękniejsze kobiety świata: Jean Shrimpton, Catherine Deneuve, Marie Helvin. Choć karierę zaczynał jako fotograf mody w magazynie «Vogue», z czasem stał się również reportażystą, utrwalającym egzotyczne obrazy Brazylii, Afganistanu, Nowej Gwinei i Wietnamu."13

Nawiązania do atmosfery Londynu lat 60. pojawiają się w „Powiększeniu” wiele razy w sposób mniej lub bardziej wyraźny. Na przykład właścicielka sklepu $\mathrm{z}$ antykami sprzedaje go, by gdzieś wjechać $\mathrm{i}$ jako jedno $\mathrm{z}$ miejsc podaje Maroko, gdzie, jak wiadomo nad Atlantykiem znajduje się Essaouira, zwana mekką hipisów. W filmie Antonioni eksponuje kolor fioletowy. Fioletowe jest tło fotograficzne w studio Thomasa, a w jednej ze scen zaakcentowane są spodnie tej samej barwy przechodzącej ulicą dziewczyny. „W latach 60. fiolet stał się kolorem buntu i przemian, uznawano go za niekonwencjonalny i prowokujący, zaś odcienie fioletu stały się symbolem młodości i poszukiwania wolności." ${ }^{14}$ Oczywiście można odwołać się do chrześcijańskiej symboliki, gdzie fiolet łączy się przecież z cierpieniem, oczekiwaniem, pokorą, żałobą, ale również modlitwą i poszukiwaniem duchowych wartości i sensu życia. Być może Antonioni mówi o jednym i o drugim.

To kipienie kulturowe, ten świat pełen pozorów i blagi, zostały w filmie „Powiększenie” zestawione ze spokojem parku, skrywającego tajemnicę morderstwa, której Thomas nie jest w stanie rozwikłać.

Jest w początkowej sekwencji filmu Antonioniego scena, która pozostaje w relacji do fotograficznego postrzegania świata. Oto Thomas odwiedza Billa swojego sąsiada - młodego malarza. Jego abstrakcyjne obrazy składają się z wielu „małych kolorowych punkcików o wyraźnej wymowie dramatycznej." 15 Bill mówi o swoich pracach:

${ }^{13}$ http://www.planeteplus.pl/dokument-david-bailey-mistrz-fotografii_35384 [dostęp 18.05.2017].

${ }^{14}$ https://pl.wikipedia.org/wiki/Barwa_fioletowa [dostęp 25.05.2017.]

${ }^{15}$ M. Antonioni, Scenariusze, Wydawnictwa Artystyczne i Filmowe, Warszawa 1976. 
„BILL: Nigdy nie wiem, co z nich wyjdzie. To chaos. Dopiero później znajduje jakiś punkt zaczepienia, jak ta noga. Wtedy wszystko zaczyna się układać. To jak rozwiązywanie zagadki kryminalnej." ${ }^{\prime 16}$

Sztuka jawi się jako zakodowana rzeczywistość. Thomas próbuje w fotografii, której powiększenie niemal obsesyjnie wykonuje, doszukać się dowodu zbrodni. Zauważa, że coś z tą fotografią jest nie tak, kiedy analizuje spojrzenia osób sfotografowanych. Zaniepokojone trafiają one poza ramy kadru.

Autotematyzm stanowi najbardziej istotny problem twórczości Antonioniego. Zastanawia się on w swoich dziełach nie tylko nad kondycją ludzką, ale również nad sytuacją artysty i jego dzieła, a szczególnie dzieła opartego na rzeczywistości, w dużej mierze ją reprodukującego i kreującego jednocześnie. To podejście rozszerza się na pytania egzystencjalne i ontologiczne. Czy możliwe jest poznanie i jakie są jego granice, jakie jest miejsce człowieka-artysty w świecie? - to pytania, które pojawiają się w wielu jego filmach, a w „Powiększeniu” szczególnie. Ten film posiada wiele pięter interpretacyjnych, nieustannie zmuszając do nowych analiz i refleksji. Reżyser prowadzi grę $\mathrm{z}$ widzem nie tylko na poziomie fabuły i medium, ale sięga głębiej, do literackiej warstwy filmu. Bo oto nie dość, że inspiruje się opowiadaniem Cortázara, którego akcję przenosi z Paryża do Londynu, to również autora opowiadania „Babie lato” przenosi ze świata realnego do świata filmu i każe mu odegrać rolę bezdomnego, który w filmie jest jak najbardziej realny. Dzięki temu uzyskuje wielopiętrowe zapętlenie interpretacyjne, a opowieść staje się parabolą. Stosuje kolista narrację, zamykając akcję w ciągu 24 godzin. Na końcu filmu wraca niejako do jego początku, do kolejnego poranka. Bohater jest już teraz zupełnie innym człowiekiem, jakby wrócił z dalekiej podróży.

Należy też zwrócić uwagę, że grający Thomasa, David Hemmings, był w zasadzie aktorem jednej roli, która ciągnęła się za nim przez całe jego życie, nie dając szansy na podjęcie równie interesującego zadania. Nie mógł on uciec od tego chłopaka $\mathrm{z}$ aparatem i zawsze postrzegano go przez pryzmat tego filmu. Podobnie, jak już wspomniałam, jest ze sceną sesji fotograficznej z Veruschką. Uwodzi ona swoim erotyzmem, którego jednocześnie tam nie ma. Widz oczekuje w napięciu tego erotycznego spełnienia, mimo iż dobrze wie, że ono nigdy nie nastąpi. Mistrz Antonioni, którego filmy pozornie pozbawione były akcji i dramaturgii, daje lekcję, jak dramaturgię i napięcie budować z pozornie błahych sytuacji, jak dodawać do nich kolejne poziomy interpretacyjne. Tak właśnie jest w przypadku „Powiększenia”, gdzie okazuje się, że rzeczywistość poza kadrem jest ważniejsza, bo niesie zupełnie inny kontekst pozornie jednoznacznego obrazu. To na co patrzy bohaterka fotografii zrobionej przez Thomasa w parku,

${ }^{16}$ M. Antonioni, Powiększenie, op.cit. 
jest o wiele bardziej istotne, niż banalna schadzka kochanków w parku. To właśnie tam kryje się tajemnica, której i tak nie jesteśmy w stanie ani my, jako widzowie, ani Thomas, jako bohater filmu, odgadnąć. W opowiadaniu Julio Cortázara „Babie lato” zatraca się granica między narratorem, autorem i bohaterem, a także przestrzenią, która posiada zdolność opowiadania o zdarzeniach. Pisarz zadaje pytanie, kto powinien pisać, czy może sama maszyna do pisania. Podobnie pyta też o podmiot fotografii: a może to sam aparat fotografuje, otwór - czyli przysłona, która na chwilę się otwiera, by wpuścić wiązkę światła i umożliwić utrwalenie obrazu na kliszy? Autor „Babiego lata” opisuje niejako swoje doświadczenia $\mathrm{z}$ fotografowaniem, a w tekście unosi się niepokojąca aura. Jednakże bohater/narrator pozostaje bezsilny wobec dramatycznej sytuacji, którą udało mu się zauważyć. Trochę inaczej jest z bohaterem „Powiększenia”, czego świadectwem może być ostatnia scena. Antonioni każe Thomasowi podjąć absurdalna grę i porzucić wiarę w pozornie obiektywnie oglądaną rzeczywistość. Thomas podnosi w końcu nieistniejącą piłeczkę i rzuca nią, a widz słyszy po chwili, jak mimowie grają tą nieistniejącą piłeczką i nieistniejącymi rakietami w tenisa. Tym razem to dźwięk poszerza granice rzeczywistości. Pytanie czy tylko rzeczywistości filmowej? Być może Antonioni chciał zwrócić uwagę na absurd świata i życia w dążeniu do unicestwienia i do śmierci. Jak napisał Mariusz Kubik: „To co wyróżnia prozę latynoamerykańską, zwykło się często określać mianem absurdu. (...) Ale ów taniec na linie, balans pomiędzy realnością i fikcją nie oznacza zagubienia literackiej intencji, czy wyalienowania. Cytowane przy omawianiu jednego z tomów opowiadań Cortázara zdanie Antoine’a Artaud: «Nigdy realne, lecz zawsze prawdziwe» najlepiej oddaje intencję argentyńskiego pisarza, zawdzięczającego tak wiele francuskim surrealistom." ${ }^{17}$ Pisząc o filmie "Powiększenie” można zgodzić się z opinią krytyka i historyka filmu, Jerzego Płażewskiego, który napisał: „Kiedy Antonioni pokazuje widzom owo demaskujące zdjęcie, to choć uzyskane super precyzyjnym anastygmatem, przypomina wręcz płótno impresjonisty, mogące znaczyć wszystko lub nic. Szydząc z zarozumiałej pewności siebie fotografika Antonioni szydzi z samego siebie."18

Warto zwrócić jeszcze uwagę na czołówkę filmu i napis „The end”, ponieważ $\mathrm{w}$ tym zawiera się całe paraboliczne przesłanie filmu. Litery tytułu filmu „Blow-up" i reszta napisów czołowych są przezroczyste. Widać przez nie fotografa oraz pozującą modelkę. Uzyskujemy w rezultacie tylko wycinki rzeczywistości, fragmenty ludzkich postaci. Natomiast napis kończący film „The end” to czarne, proste litery. Pojawiają się one na zielonym trawniku ujętym z góry w momencie, kiedy Thomas idący wolnym krokiem i trzymający nonszalancko za pasek

17 M. Kubik, Julio Cortázar czyli gra wyobraźni, http://gazeta.us.edu.pl/node/212851 \{dostęp 25.05.2017].

${ }^{18} \mathrm{http} / / /$ archiwum.stopklatka.pl/news/jerzy-plazewski-przedstawia-filmy-ktore-warto-znacpowiekszenie 
aparat fotograficzny, znika z kadru. Czyżby Antonioni chciał nam powiedzieć, że fotografia zaciemnia ten fragmentaryczny obraz świata, który widzieliśmy na początku? A Thomas, to być może niewierny Tomasz, który ponosi klęskę, ponieważ przestaje wierzyć $\mathrm{w}$ fotografowaną, a być może i realną, rzeczywistość? Słusznie pisze Wojciech Nowicki: „Pokrętna prawda fotografii jest wyłącznie w tym, co jest nam dane do zobaczenia; fotografia nie tłumaczy świata, ale pokazuje wyrwane obrazy, jak kartki z książki, gdzie tekst zaczyna się w pół słowa i kończy równie gwałtownie. (...) Pozwala podglądać przez dziurkę od klucza, ale skąpi komentarza. Fotografia na śmieszność naraża każdego, kto za jej pomocą chciałby wyjaśniać świat (...).”19

\section{Tytuł: POWIĘKSZENIE (BLOW UP);}

Kraj i rok produkcji: Wielka Brytania 1966;

Reżyseria: Michelangelo Antonioni;

Scenariusz: Michelangelo Antonioni, Tonino Guerra;

Inspiracja: Julio Cortázar - opowiadanie „Las babas del diablo” („Babie lato”); Zdjęcia: Carlo Di Palma;

Scenografia: Assheton Gordon;

Muzyka: Herbie Hancock; piosenka Troll On - zespół The Yardbirds;

Montaż: Frank Clarke;

Producent: Carlo Ponti - Bridge Films;

Obsada: David Hemmings -Thomas, Vanessa Redgrave - Jane, Peter Bowles Ron, Sarah Miles - Patricia, Veruschka von Lehndorff - Verushka, John Castle - Bill, Gillian Hills - blondynka, Jane Birkin - szatynka, Harry Hutchinson - sprzedawca w antykwariacie, Susan Broderick - właścicielka antykwariatu.

\section{Bibliografia:}

Antonioni Michelangelo, Scenariusze, Wydawnictwa Artystyczne i Filmowe, Warszawa 1976. Roland Barthes, Światło obrazu. Uwagi o fotografii, Wydawnictwo Aletheia, Warszawa 1996. Bazin Andre, Ontologia obrazu fotograficznego, za: http://residence.republika.pl/bazin,andrE9,ontologia,obrazu,fotograficznego.shtml (18.05.2017.)

Cortázar Julio, Opowiadania zebrane. T.1., tł. Chądzyńska Zofia, Wydawnictwo Muza, Warszawa 1999. Książek-Konicka Hanna, Michelangelo Antonioni, Wydawnictwa Artystyczne i Filmowe, Warszawa 1970.

Kubik Mariusz, Julio Cortázar czyli gra wyobraźni, http://gazeta.us.edu.pl/node/212851.

Michelangelo Antonioni, red. Żmudziński Bogusław, Wyd. Rabid, Kraków 2004.

Nowicki Wojciech, Dno oka. Eseje o fotografii, Wyd. Czarne, Wołowiec, 2010, cyt. za: http://agaczyta.blox.pl/2012/12/Dno-oka-Eseje-o-fotografii-Wojciech-Nowicki.html\#axzz4hbGWl3q8

${ }_{19}$ http://agaczyta.blox.pl/2012/12/Dno-oka-Eseje-o-fotografii-Wojciech-Nowicki.html\# axzz4hbGWl3q8 
Sikora Sławomir, Fotograficzna przygoda Antonioniego: Powiększenie, "Kwartalnik Filmowy” 1993, nr 02, s. 37.

Sontag Susan, O fotografii, Wyd. Karakter, Kraków 2009.

Spojrzenie Antonioniego, red. Paulina Kwiatkowska, Piotr Sadzik, Wyd., Mammal, Warszawa 2015. Wojtasik Paulina, Psychologia "Powiększenia”, http://www.racjonalista.pl/kk.php/t,4363 [dostęp 25.05.2017.].

http://bartek-zielinski.com/blogfilmowy/powiekszenie/

\section{Streszczenie:}

Artykuł traktuje o filmie „Powiększenie” Michelangelo Antonioniego, arcydzieła kina autorskiego, którego scenariusz oparty został na opowiadaniu Julio Cortazara. Ten niemal klasyczny film ma charakter autotematyczny i podejmuje problem poznania świata przez obraz, a szczególnie poprzez fotografię. Odnosi się również do problemu kreacji w świecie popkultury. Jest jednak przede wszystkim metaforycznym dyskursem na temat bycia człowieka w świecie. Autorka podejmuje analizę filmu, w kontekście fotografii, która stanowi fabularną i estetyczną materię, a zarazem pozwala podjąć uniwersalne rozważania.

Słowa kluczowe: Michelangelo Antonioni, autotematyzm, epistemologia, fotografia, metafora, obraz, „Powiększenie”, voyeuryzm.

\section{Photography in the film „Blowup” by Michelangelo Antonini}

\section{Summary}

The article deals with „Blowup” movie by Michelangelo Antonioni, a masterpiece of the auteur cinema, which script is based on the short story of Julio Cortazar. This almost classic movie has autothematic character and takes up the problem of getting to know the world through image, and especially through photograph. It also refers to the problem of creation in the pop culture world. However, above all it is a metaphorical discourse about being human in the world. The author of article undertakes analysis of film in the context of photography, which is a fictional and aesthetic base and also allows to make universal considerations.

Keywords: Michelangelo Antonioni, „Blow up”, epistemology, mise en abyme, metaphor, picture, photography, voyeurism. 